\title{
Phaeodactylum Tricornutum as a Potential Phytoremediator of Sea and Fresh Waters
}

\author{
Stanisław Listwan ${ }^{1}$, Wiktor Tokarek ${ }^{1}$, Krzysztof Kleszez ${ }^{2}$, Magdalena Chowaniec ${ }^{1}$, Zofia Porębska ${ }^{1}$, \\ Katarzyna Krawczyk ${ }^{1}$, Monika Bojko ${ }^{1}$, Dariusz Latowski ${ }^{1}$ \\ ${ }^{1}$ Department of Plant Physiology and Biochemistry Faculty of Biochemistry, Biophysics and Biotechnology \\ Jagiellonian University, Gronostajowa 7, 30-387 Kraków, Poland \\ stlistwan@gmail.com; wiktor.tokarek@gmail.com; magdalena.chowaniec@student.uj.edu.pl; \\ zosia.porebska@student.uj.edu.pl; katarzyna4.krawczyk@student.uj.edu.pl; m.bojko@uj.edu.pl; \\ dariuszlatowski@gmail.com \\ ${ }^{2}$ State Higher Vocational School in Tarnów \\ Poland \\ k.kleszcz@gmail.com
}

\begin{abstract}
Phaeodactylum tricornutum is commonly spotted marine diatom species. It is known of its advantages as model organism used in many scientific applications, such as sequenced genome and ease culture. Toxic elements pollution is frequent issue in developing countries since elimination of such contamination is expensive, and dangerous to human health. Bioremediation is often seen as a solution of this problem. In this work $P$. tricornutum is analyzed as a potential bioremediating agent in sea and freshwater. Ability to growth in different concentrations of arsenic, cadmium and mercury is tested. It is investigated if $P$. tricornutum is able to proliferate in freshwater samples taken from river. At last concentration of every listed element is evaluated before and after culture. It is concluded that $P$. tricornutum has huge potential as a bioremediating organism.
\end{abstract}

Keywords: Phaeodactylum Tricornutum, Arsenic, Cadmium, Mercury, Bioremediation.

\section{Introduction}

Diatoms are ubiquitous part of marine as well as inland ecosystems. This group of organisms is considered to be responsible for $20 \%$ of Earth net primary production of biomass and $40 \%$ for marine biomass production[1, 2]. Diatoms play also a significant role in global silica cycle [3]. Phaeodactylum tricornutum belongs to group Pennateae, and it is only known species in genus Phaeodactylum. Due to the fact that its genome has been sequenced, and to easiness of culturing it is often used as a model organism [4]. One of the most interesting properties of P. tricornutum is ability to occur in at least four different morphological forms: fusiform, oval, triradiate and cruciform [5 - 7]. Fusiform and oval morphotypes seems to be most abundant of all observed, and the transformation from fusiform to the oval morphotype and often in opposite direction was observed $[4,8]$. Triradiate morphotype is not commonly spotted in laboratory cultured $P$. tricornutum and some authors suggest that it is unusual morphotype in $P$. tricornutum lifecycle [9]. Despite difficulties in sustaining triradiate morphotype in culture it is often isolated from natural environment $[4,8]$. Cruciform morphotype has been characterized quite recently and it is considered rare. It is believed that cruciform morphotype occurrence is strongly dependent on low temperature of culture [7]. It is assumed that morphological changes in P. tricornutum are effect of environmental diversity [10].

Since toxic elements can be accumulated by many organisms, abundance of such elements is an important worldwide issue [11, 12]. Toxicity of such elements as cadmium, mercury, and arsenic is well described [12 - 14].

Bioremediation is often considered as a cheaper and safer approach to eliminating toxic elements from the environment than traditional physicochemical methods $[15,16]$.

The aim of this work was to asses toxicity of those elements on P. tricornutum and to evaluate suitability of this species in bioremediation of polluted sea and fresh water.

\section{Materials And Methods}

Phaeodactylum tricornutum strain 1055/1 diatoms (obtained from Culture Collection of Algae and Protozoa (CCAP); UK) were cultured in Guillard's f/2 medium [17]. Temperature of culture media was maintained at $12^{\circ} \mathrm{C}$ and 
14/10h light to dark regime was used [18]. The intensity of light used to illuminate culture flasks (measured with Skye PAR Quantum light meter) was $48 \mu \mathrm{mol} \cdot \mathrm{m}^{-2} \cdot \mathrm{s}^{-1}$. For assessing $P$. tricornutum ability to growth in freshwater, water from two watercourses: Potok Gromiecki and Biała Przemsza in south Poland was obtained. Both rivers flows through region considered by polish Chief Inspectorate of Environmental Protection as exposed to heavy metals pollution. Freshwater samples from listed rivers was taken and transported to laboratory within three hours and frozen. Before inoculation of diatoms in freshwater the concentration of selected elements and ions was measured using inductively coupled plasma atomic emission spectroscopy (ICP-OES) and titration with silver nitrate. No addition of any nutrients was used when freshwater was applied as culture medium for diatoms. When in Guillard's $\mathrm{f} / 2$ medium was used following compounds were applied as a source of toxic elements: sodium arsenate(V) $\left(\mathrm{Na}_{2} \mathrm{HAsO}_{4}\right)$, mercury(II) chloride $\left(\mathrm{HgCl}_{2}\right)$, cadmium chloride $\left(\mathrm{CdCl}_{2}\right)$. Following concentrations of metallic ions were used: $\mathrm{Cd}^{2+}-0.1,1,2 \mathrm{mg} / \mathrm{L} ; \mathrm{Hg}^{2+}-0.01,1,10 \mathrm{mg} / \mathrm{L}$; total concentration of arsenic atoms were: $0.05 \mathrm{mg} / \mathrm{L}, 0.4 \mathrm{mg} / \mathrm{L}$ and $10 \mathrm{mg} / \mathrm{L}$. Listed concentrations were chosen in the way that the lowest ones fall in the range of permissible levels and higher ones exceeds those levels. All media were sterilized in $121^{\circ} \mathrm{C}$ by $20 \mathrm{~min}$. Before inoculation in medium, stock culture of diatoms was centrifuged (20 min, $300 \mathrm{rcf}$, $12^{\circ} \mathrm{C}$ ) to remove old medium. Stock cultures of diatoms were not treated with toxic elements before experiments. On the beginning and at the end of experiments concentrations of $\mathrm{As}, \mathrm{Cd}$ and $\mathrm{Hg}$ were measured using atomic absorption spectrometry (AAS) in case of arsenic, ICP-OES in case of $\mathrm{Cd}$ and $\mathrm{Hg}$. Growth of diatoms was measured spectrophotometrically as a change in optical density of medium at a wavelength $600 \mathrm{~nm}\left(\mathrm{OD}_{600}\right)$. Every experiment was conducted in triplicate.

\section{Results and Discussion}

\subsection{P. Tricornutum Growth in Metal Polluted Media}

Growth of diatom cultures treated with two lowest concentrations $(0.1 \mathrm{mg} / \mathrm{L}$ and $1 \mathrm{mg} / \mathrm{L})$ of cadmium does not differ significantly from growth of control cultures, however the highest concentration $(20 \mathrm{mg} / \mathrm{L})$ is limiting growth approximately by half (Fig. 1A). In the case of mercury, the lowest concentration $(0.01 \mathrm{mg} / \mathrm{mL})$ does not seem to influence growth in any way. In two higher concentrations $(1 \mathrm{mg} / \mathrm{L}$ and $10 \mathrm{mg} / \mathrm{L})$ of mercury, growth cannot be observed (Fig. 1B). P. tricornutum treated with two lower concentrations $(0.05 \mathrm{mg} / \mathrm{L}$ and $0.4 \mathrm{mg} / \mathrm{L})$ of arsenic shows similar growth to control cultures. The highest concentration of arsenic not only causes limitation of growth but also delay the lag phase of growth by approximately 5 days (Fig. 1C).
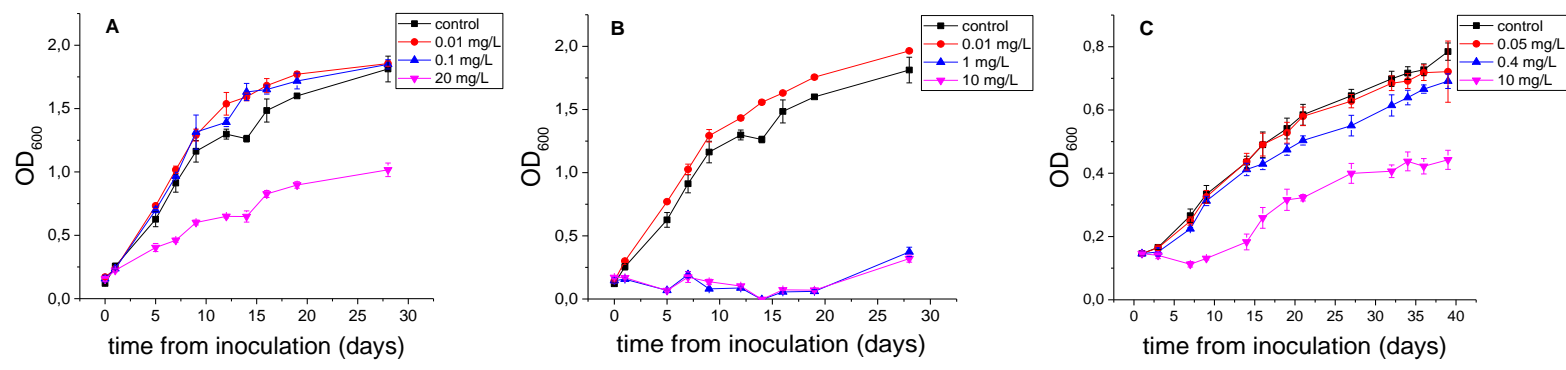

Fig. 1: Growth of diatoms in: cadmium (A), mercury (B) and arsenic (C) polluted Guillard's media showed as change in $\mathrm{OD}_{600}$ compared to control.

Since diatoms were not previously treated with analyzed elements it was impossible for them to acclimatize to described conditions before the beginning of the experiment. That leads to statement that in case of most of analyzed elements concentrations $P$. tricornutum is able to growth even if appearance of toxic elements is sudden and they concentrations are considered as high. This property may be found valuable when considering use of $P$. tricornutum as bioremediating agent. High doses of all examined elements are toxic to $P$. tricornutum, however it is most noticeable in mercury where concentration $1 \mathrm{mg} / \mathrm{L}$ halts growth completely. Nevertheless $P$. tricornutum shows significant resistance to examined toxic elements. In this study previous reports on relatively high resistance to cadmium and mercury was confirmed [19].

\subsection{Growth in Freshwater from Polluted Rivers}

Evaluated concentrations of chosen elements and ions in taken water samples are listed in table 1. No particular exceeding over standards was noted with exception for chlorides in Potok Gromiecki where permitted concentration is exceeded, for Biała Przemsza this parameter was within the norm. Water from both rivers even considering high concentration of chlorides in Potok Gromiecki, should be classified as freshwater [20]. 
Table 1: Evaluated concentrations of chosen elements and ions in used water samples (*below limit of detection), elements which concentration was below the limit of detection in both samples were omitted in the table

\begin{tabular}{|c|c|c|c|c|}
\hline \multirow[t]{2}{*}{ Element/ion } & \multicolumn{2}{|c|}{ Potok Gromiecki } & \multicolumn{2}{|c|}{ Biala Przemsza } \\
\hline & Mean & $S D$ & Mean & $S D$ \\
\hline & \multicolumn{4}{|c|}{ Main elements $\left(\mathrm{mg} \cdot \mathrm{L}^{-1}\right)$} \\
\hline $\mathbf{N a}$ & 3870.00 & 15.37 & 40.11 & 0.39 \\
\hline $\mathbf{S}$ & 843.99 & 3.64 & 217.82 & 1.20 \\
\hline $\mathbf{C a}$ & 391.20 & 2.86 & 68.27 & 0.36 \\
\hline Mg & 359.46 & 5.40 & 38.73 & 0.13 \\
\hline $\mathbf{K}$ & 150.74 & 3.5 & 10.0 & 0.2 \\
\hline $\mathbf{S i}$ & 14.85 & 0.15 & 12.62 & 0.12 \\
\hline $\mathrm{Sr}$ & 5.28 & 0.04 & 0.16 & 0.002 \\
\hline B & 2.10 & 0.02 & 0.28 & 0.01 \\
\hline Se & 1.15 & 0.15 & $*$ & 0.30 \\
\hline $\mathrm{Cl}^{-}$ & 17718.00 & titration & 61.04 & titration \\
\hline \multirow[t]{2}{*}{$\mathrm{HCO}_{3}^{-}$} & 175.68 & titration & 146.40 & titration \\
\hline & \multicolumn{4}{|c|}{ Trace elements $\left(\mathrm{mg} \cdot \mathbf{L}^{-1}\right)$} \\
\hline $\mathbf{B a}$ & 0.045 & 0.002 & 0.021 & 0.001 \\
\hline $\mathbf{C r}$ & 0.005 & 0.0005 & 0.002 & 0.0005 \\
\hline Cs & 0.083 & 0.002 & 0.055 & 0.004 \\
\hline $\mathbf{G a}$ & 0.017 & 0.0004 & 0.010 & 0.003 \\
\hline $\mathbf{L i}$ & 0.813 & 0.008 & 0.007 & 0.0002 \\
\hline Mn & 0.014 & 0.001 & 0.005 & 0.0003 \\
\hline Mo & 0.030 & 0.006 & 0.041 & 0.001 \\
\hline $\mathbf{N i}$ & 0.003 & 0.002 & 0.012 & 0.001 \\
\hline $\mathbf{P}$ & 0.409 & 0.041 & 0.237 & 0.038 \\
\hline $\mathbf{P b}$ & 0.003 & 0.006 & 0.012 & 0.002 \\
\hline $\mathbf{R b}$ & 0.237 & 0.003 & 0.019 & 0.001 \\
\hline Sn & 0.124 & 0.007 & 0.062 & 0.005 \\
\hline TI & 0.008 & 0.022 & 0.003 & 0.022 \\
\hline $\mathbf{U}$ & 0.003 & 0.004 & 0.005 & 0.006 \\
\hline $\mathbf{V}$ & 0.201 & 0.005 & 0.037 & 0.001 \\
\hline
\end{tabular}

Growth of diatom in freshwater was limited when compared to the control however it was clearly observable. P. tricornutum grown in the freshwater from Potok Gromiecki showed high differentiation of growth when compared to grown in control and Biała Przemsza (Fig. 2). 

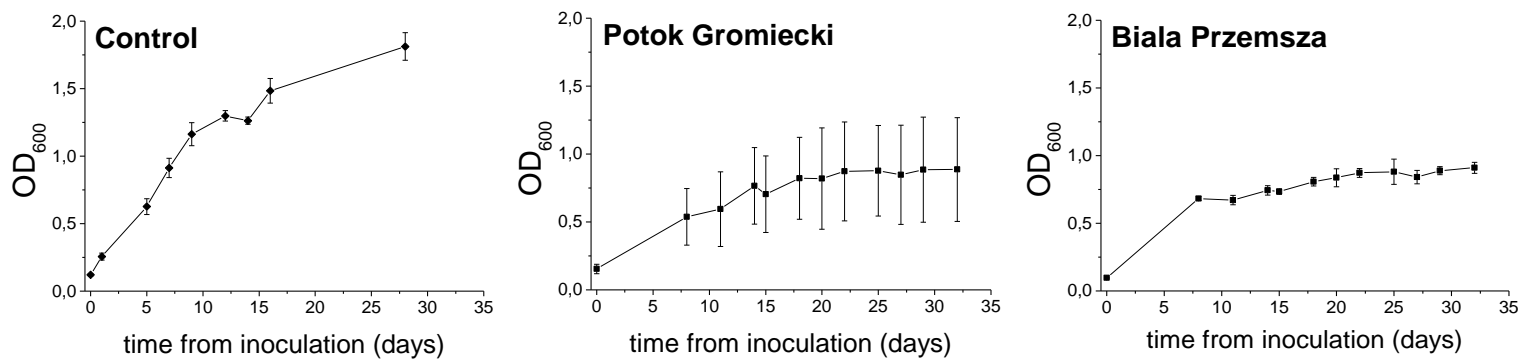

Fig. 2: Growth of diatoms in freshwater taken from rivers Biała Przemsza and Potok Gromiecki measured spectrophootometrically as change in $\mathrm{OD}_{600}$, as control $\mathrm{f} / 2$ Guillard's medium was used.

Despite the fact that growth in freshwater was reduced when comparing it to that in control medium, ability of growth in freshwater without any addition of nutrients can be considered as another important attribute of $P$. tricornutum which increase usability of this diatom species in bioremediation.

\subsection{Changes of Arsenic, Cadmium and Mercury Concentrations during Culture}

In media containing listed toxic elements change of concentrations of those elements was observed. In lower elements concentrations $(0.05 \mathrm{mg} / \mathrm{L}$ and $0.4 \mathrm{mg} / \mathrm{L}$ for arsenic, $0.1 \mathrm{mg} / \mathrm{L}$ for cadmium and $0.01 \mathrm{mg} / \mathrm{L}$ for mercury) drop of content of listed elements was noticed. In case of media with arsenic and media with cadmium, decrease of concentration reached even $60 \%$ of value at the beginning of the culture. In higher initial concentrations, such decrease could not have been observed (Fig. 3).
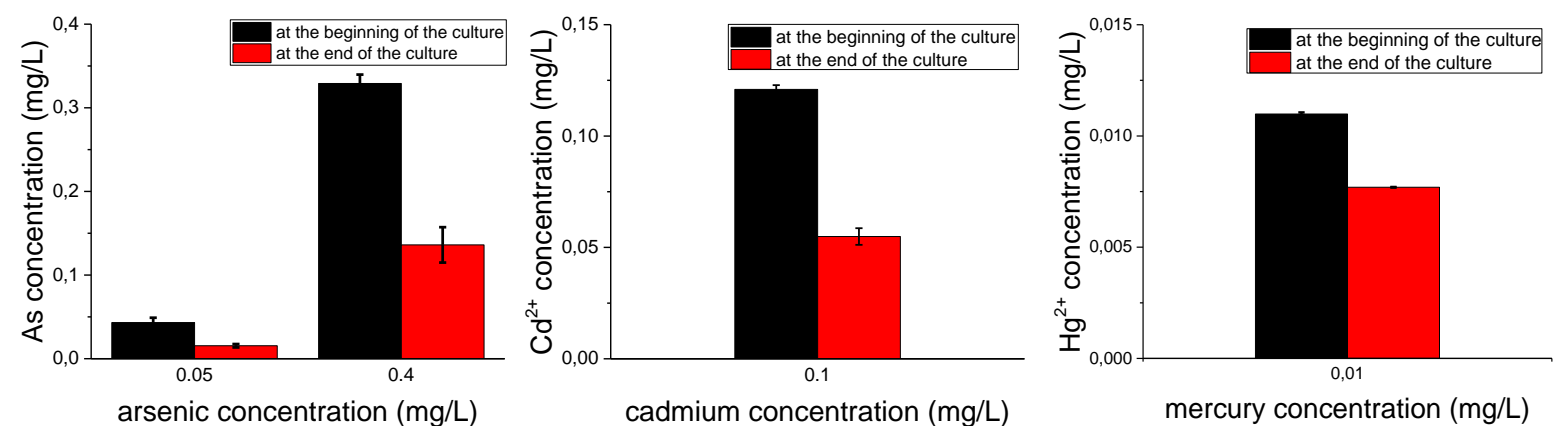

Fig. 3: Comparison of concentrations of toxic elements in the culture medium at the beginning and the end of the culture. Only lower initial concentrations are presented on the graph $(0.05 \mathrm{mg} / \mathrm{L}$ and $0.4 \mathrm{mg} / \mathrm{L}$ for arsenic, $0.01 \mathrm{mg} / \mathrm{L}$ for mercury and $0.1 \mathrm{mg} / \mathrm{L}$ for cadmium) because for higher concentrations no significant changes were observed.

In lower concentrations of every examined element $P$. tricornutum showed ability to reduce concentration of those elements in culture medium. Mechanisms of reducing mercury has been described [21], however mechanisms of reducing arsenic and cadmium concentrations remain unclear and this matter requires more studies. Nevertheless ability of $P$. tricornutum to reduce toxic elements concentration in their environment is crucial for future application of this microorganism in bioremediation of polluted water.

\section{Conclusions}

Phaeodactylum tricornutum is able to survive and proliferate in media containing relatively high amounts of such elements as arsenic, cadmium and mercury. This diatom species is relatively resistant to sudden changes of the environment. Despite the fact that $P$. tricornutum is a marine diatom it shows the ability of growth even in freshwater. Described diatom species is capable of reducing arsenic, cadmium and mercury concentration in its environment. Taken together those properties indicate that $P$. tricornutum has large potential as the bioremediator and could be applied as an effective phytoremediator both of sea and fresh waters.

\section{Acknowledgements}

This work was supported by KNOW - The Faculty of Biochemistry, Biophysics and Biotechnology of Jagiellonian University a partner of Leading National Research Center (KNOW) supported by the Minister of Science and Higher Education No. A1/384. 


\section{References:}

[1] P. G. Falkowski, R. T. Barber, and V. Smetacek, "Biogeochemical controls and feedbacks on ocean primary production,” Science, vol. 281, no. 5374. pp. 200-206, 1998.

[2] C. B. Field, M. J. Behrenfeld, J. T. Randerson, and P. Falkowski, "Primary production of the biosphere: Integrating terrestrial and oceanic components," Science, vol. 281, no. 5374, pp. 237-240, 1998.

[3] P. Treguer, D. M. Nelson, A. J. Van Bennekom, D. J. DeMaster, A. Leynaert, and B. Queguiner, "The silica balance in the world ocean: A reestimate," Science, vol. 268, no. 5209, pp. 375-379, 1995.

[4] A. De Martino, A. Meichenin, J. Shi, K. Pan, and C. Bowler, "Genetic and phenotypic characterization of Phaeodactylum tricornutum (Bacillariophyceae) accessions," J. Phycol., vol. 43, no. 5, pp. 992-1009, 2007.

[5] M. A. Borowitzka and B. E. Volcani, "The polymorphic diatom Phaeodactylum tricornutum: ultrastructure of its morphotypes," J. Phycol., vol. 14, no. 1, pp. 10-21, 1978.

[6] M. A. Borowitzka, M. L. Chiappino, and B. E. Volcani, "Ultrastructure of a chain-forming diatom Phaeodactylum tricornutum," J. Phycol., vol. 13, no. 2, pp. 162-170, 1977.

[7] L. He, X. Han, and Z. Yu, "A rare Phaeodactylum tricornutum cruciform morphotype: Culture conditions, transformation and unique fatty acid characteristics," PLoS One, vol. 9, no. 4, 2014.

[8] B. Tesson, C. Gaillard, and V. Martin-Jézéquel, "Insights into the polymorphism of the diatom Phaeodactylum tricornutum Bohlin," Botanica Marina, vol. 52, no. 2. pp. 104-116, 2009.

[9] J. C. Lewin, R. A. Lewin, and D. E. Philpott, "Observations on Phaeodactylum tricornutum," Microbiol. Soc. J., vol. 18, no. 1, pp. 418-426, 1958.

[10] A. De Martino, A. Bartual, A. Willis, A. Meichenin, B. Villazán, U Maheswari and C. Bowler, "Physiological and molecular evidence that environmental changes elicit morphological interconversion in the model diatom Phaeodactylum tricornutum," Protist, vol. 162, no. 3, pp. 462-481, 2011.

[11] S. Clemens and J. F. Ma, "Toxic heavy metal and metalloid accumulation in crop plants and foods," Annu. Rev. Plant Biol., vol. 67, no. 1, pp. 489-512, 2016.

[12] B. K. Mandal and K. T. Suzuki, "Arsenic round the world: A review," Talanta, vol. 58, no. 1, pp. 201-235, 2002.

[13] M. P. Benavides, S. M. Gallego, and M. L. Tomaro, "Cadmium toxicity in plants," Brazilian Journal of Plant Physiology, vol. 17, no. 1.pp. 21-34, 2005.

[14] M. Patra and A. Sharma, "Mercury toxicity in plants," Bot. Rev., vol. 66, no. 3, pp. 379-422, 2000.

[15] A. Malik, "Metal bioremediation through growing cells," Environment International, vol. 30, no. 2. pp. 261-278, 2004.

[16] C. Garbisu and I. Alkorta, "Basic concepts on heavy metal soil bioremediation," Eur. J. Miner. Process. Environ. Prot., vol. 3, no. 1, pp. 58-66, 2003.

[17] R. R. L. Guillard, "Culture of phytoplankton for Feeding Marine Invertebrates," in Culture of Marine Invertebrate Animals, 1975, pp. 29-60.

[18] M. Bojko et al., "Temperature effect on growth, and selected parameters of Phaeodactylum tricornutum in batch cultures," Acta Biochim. Pol., vol. 60, no. 4, pp. 861-864, 2013.

[19] J. Horvatić and V. Peršić, "The Effect of $\mathrm{Ni}^{2+}, \mathrm{Co}^{2+}, \mathrm{Zn}^{2+}, \mathrm{Cd}^{2+}$ and $\mathrm{Hg}^{2+}$ on the growth rate of marine diatom Phaeodactylum tricornutum Bohlin: Microplate growth inhibition test," Bull. Environ. Contam. Toxicol., vol. 79, no. 5, pp. 494-498, 2007.

[20] DOE (1994) "Handbook of methods for the analysis of the various parameters of the carbon dioxide system in sea water" version 2, A. G. Dickson and C. Goyet, eds., ORNL/CDIAC-74.

[21] G. F. Deng, T. W. Zhang, L. M. Yang, and Q. Q. Wang, "Studies of biouptake and transformation of mercury by a typical unicellular diatom Phaeodactylum tricornutum," Chinese Sci. Bull., vol. 58, no. 2, pp. 256-265, 2013. 